\title{
STIMULATION ATTITUDIONAL REFLEX EXERCISE LEBIH BAIK DIBANDINGKAN DENGAN PRONE POSITION WEDGE EXERCISE TERHADAP HEAD CONTROL PADA ANAK CEREBRAL PALSY SPASTIK QUADRIPLEGI DI RS RAJAWALI CITRA BANTUL, YOGYAKARTA
}

\author{
Damha Al Banna ${ }^{1}$, I Putu Gede Adiatmika' ${ }^{2}$ M. Irfan ${ }^{3}$, \\ I Putu Adiartha Griadhi ${ }^{4}$, Luh Putu Ratna Sundari ${ }^{5}$, Sugijanto ${ }^{6}$ \\ ${ }^{1}$ Program Studi Magister Fisiologi Keolahragaan Universitas Udayana Bali \\ ${ }^{2,4,5}$ Fakultas Kedokteran Universitas Udayana Bali \\ ${ }^{3}$ Program Studi S1 dan Profesi Fisioterapi Universitas 'Aisyiyah Yogyakarta \\ ${ }^{6}$ Fakultas Fisioterapi Universitas Esa Unggul Jakarta
}

\begin{abstract}
ABSTRAK
Latar belakang: Head control adalah gangguan pada anak cerebral palsy (CP) spastik quadriplegi karena permasalahan susunan saraf pusat yang berfungsi sebagai dasar gerakan yang harus dicapai untuk perkembangan selanjutnya. Tindakan fisioterapi dapat diberikan berupa stimulation attitudional reflex exercise (SARE) dan prone position wedge exercise (PPWE). Tujuan: Penelitian ini bertujuan untuk mengetahui SARE lebih baik dibanding dengan PPWE terhadap head control pada anak CP spastik quadriplegi. Metode: Rancangan penelitian ini menggunakan eksperimental pre and post test control group design bertempat di RS Rajawali Citra Bantul. Subjek sebanyak 24 anak CP spastik quadriplegi terbagi jadi 2 perlakuan kelompok. Pada Kelompok I diberikan SARE selama 3 kali pengulangan dalam 1 jam sesi terapi dan Kelompok II diberikan PPWE selama 30 menit. Semua kelompok tersebut diberikan perlakuan 1 kali seminggu selama 6 minggu sebagai penyegaran tindakan intervensi dan diberikan edukasi kepada keluarga untuk dilakukan setiap hari di rumah. Alat ukur head control menggunakan gross motor functional measurement. Hasil: Uji statistik menggunakan paired sample t-test pada Kelompok I dan Kelompok II hasilnya $\mathrm{p}=0,001$ dimana $\mathrm{p}<0,05$ terjadi peningkatan head control. Dari independent t-test diperoleh hasil $\mathrm{p}=0,001$ dimana $\mathrm{p}<0,05$, sehingga dapat disimpulkan bahwa ada perbedaan antara Kelompok I dengan Kelompok II. Berdasarkan nilai rerata Kelompok I mengalami peningkatan head control yang lebih besar yaitu 33,19\% dibandingkan Kelompok II yang hanya mempunyai nilai 16,96\%. Simpulan: SARE lebih baik dibandingkan dengan PPWE terhadap peningkatan head control pada anak CP spastik quadriplegi
\end{abstract}

Kata kunci : Head control, SARE, PPWE 
STIMULATION ATTITUDIONAL REFLEX EXERCISE BETTER THAN PRONE POSITION WEDGE EXERCISE ON HEAD CONTROL AMONG CHILDREN WITH CEREBRAL PALSY SPASTIC QUADRIPLEGI IN RAJAWALI CITRA BANTUL HOSPITAL, YOGYAKARTA

\begin{abstract}
Background: Head control is a disorder of the cerebral palsy (CP) spastic quadriplegi due to central nervous system problems that serve as the basis of movement to be achieved for further development. Physiotherapy actions that can be given are stimulation attitudional reflex exercise (SARE) and prone position wedge exercise (PPWE). Purpose: This study aims to determine whether SARE is better than PPWE for head control in CP spastic quadriplegi. Methods: This research uses experimental pre and post test control group design is done at Rajawali Citra Bantul Hospital. Subjects were 24 children with CP spastic quadriplegi divided into 2 groups, group I was given SARE for 3 repetitions in 1 hour of therapy sessions and group II was given PPWE for 30 minutes. All groups were given treatment 1 time a week for 6 weeks as a refresher intervention and educated the family to do every day at home. Increased head control is measured by gross motor functional measurement. Result: Statistical test of paired sample t-test in group I and group II p value $=0.001$ where $(p<0.05)$ there was an increase of head control. From independent t-test $\mathrm{p}$ value $=0.001$ where $(\mathrm{p}<0.05)$, it can be concluded that there are significant differences between group I with group II. Based on the mean values in both treatment groups, the group I have larger head control improvement of $33.19 \%$ than group II which only $16.96 \%$. Conclusion: SARE is better than PPWE to increase head control on CP spastic quadriplegi
\end{abstract}

Keywords: Head control, SARE, PPWE

\title{
PENDAHULUAN
}

Cerebral palsy (CP) spastik quadriplegi adalah kelayuhan otak tidak progresif dan menetap sebagai akibat dari kerusakan otak yang terjadi selama bayi berada dalam kandungan atau periode awal kelahiran, selama proses persalinan, maupun setelah lahir. ${ }^{1,2}$

Permasalahan pada anak CP spastik quadriplegi adalah gangguan kontrol tonus postural dan gerakan yang bisa disertai deformitas pada sistem muskuloskeletal yang mengganggu aktifitas fungsional. Kondisi tersebut akan mengganggu pola tumbuh kembang motoris anak terutama problematik dasar yang sama yaitu gangguan kontrol tonus postural Dalam perkembangan gerak, head control adalah salah satu bagian dari kontrol postural. Dengan terganggunya head control maka akan mengganggu kontrol gerak dan kontrol postural, keseimbangan, dan koordinasi sehingga aktivitas fungsional sehari-hari juga akan mengalami kesulitan. Head control adalah gangguan yang sering dijumpai pada anak $\mathrm{CP}$ spastik quadriplegi karena permasalahan pada susunan saraf pusat (SSP) yang berfungsi sebagai dasar gerakan yang harus dicapai untuk perkembangan gerak selanjutnya, seperti duduk, merangkak, dan berdiri. Anak CP spastik quadriplegi yang mengalami gangguan head control akan sedikit kesulitan didalam mengontrol kepalanya karena kemampuan gerak dan otot-otot disekitar leher masih sangat lemah. $2,3,4$ 
Tindakan fisioterapi yang bisa diberikan untuk meningkatkan head control pada anak $\mathrm{CP}$ spastik quadriplegi salah satunya adalah stimulation attitudional reflex exercise (SARE) yang bertujuan untuk memberikan pembelajaran motor kontrol dalam hubungannya dengan maturitas reflex yang tertata dengan baik sehingga dalam proses menuju ke postural kontrol yang baik maka perlu menggerakkan dan menyeimbangkan kepala sehingga akan merangsang organ apparatus vestibular dalam memperoleh head control yang baik pada anak $\mathrm{CP}$ spastik quadriplegi. 5,6,7

Pemberian intervensi selanjutnya dalam mengatasi permasalahan head control adalah dengan prone position wedge exercise (PPWE) yang bertujuan untuk untuk meningkatkan mobilitas leher dan meningkatkan kekuatan otot ekstensor leher dalam melawan gravitasi sehingga dapat meningkatkan koordinasi mata terhadap lingkungan sekitar yang merupakan proses awal untuk mempertahankan head control yang baik dimana neuron motorik otot-otot mata akan mengontrol gerakan mata dan susunan saraf pusat untuk persepsi gerakan dan orientasi dalam mempertahankan posisi kepala agar tetap tegak. ${ }^{4,8}$

Penelitian ini bertujuan untuk membuktikan stimulation attitudional reflex exercise (SARE) lebih baik dibandingkan dengan prone position wedge exercise (PPWE) terhadap head control pada anak $\mathrm{CP}$ spastik quadriplegi.

\section{METODOLOGI PENELITIAN}

\section{A. Rancangan Penelitian}

Menggunakan metode eksperimental pre and post group design yang dilakukan secara random.

\section{B. Lahan serta Waktu Penelitian}

Bertempat di poliklinik fisioterapi tumbuh kembang anak RS Rajawali Citra Bantul, Yogyakarta . Waktu penelitian tanggal 15 Februari - 31 Maret 2018.
Kelompok I diberikan selama 3 kali pengulangan dalam 1 jam sesi terapi dan Kelompok II diberikan selama 30 menit. Semua kelompok tersebut diberikan perlakuan 1 kali seminggu selama 6 minggu sebagai penyegaran tindakan intervensi dan diberikan edukasi kepada keluarga untuk dilakukan setiap hari di rumah

\section{Sampel dan Populasi}

Anak CP spastik quadriplegi dengan kondisi gangguan head control di poliklinik fisioterapi tumbuh kembang anak RS Rajawali Citra Bantul, Yogyakarta yang telah memenuhi kriteria untuk sampel penelitian

\section{Cara Perolehan Subjek}

Menggunakan teknik conseccutive sample atau kuota sampel. Jumlah sampel masuk kriteria inklusi sebanyak 24 sampel. Pembagian kelompok dilakukan secara acak lokasi dari jumlah terpilih dan setiap kelompok terdiri dari 12 anak $\mathrm{CP}$ spastik quadriplegi. Kelompok I mendapatkan perlakuan stimulation attitudional reflex exercise (SARE) sedangkan Kelompok II prone position wedge exercise (PPWE).

\section{E. Prosedur Penelitian}

Alur tahap penelitian meliputi : (a) ijin untuk tempat lahan penelitian, (b) surat pernyataan persetujuan oleh orangtua subjek yang harus ditanda tangani untuk mengijinkan anak sebagai subjek sampai selesai penelitian, (c) home program yang bisa diambil mengenai penelitian ini, (d) setelah pemeriksaan selesai, sampel di kelompokkan menjadi 2 kelompok. Alat ukur kemampuan fungsional head control dengan metode pengukuran GMFM dimensi A dilakukan sebelum dan sesudah, (e) data tersebut diolah menggunakan SPSS.

\section{F. Analisis Data}

Untuk Uji statistik pada penelitian ini menggunakan : 
1. Karakteristik sampel menurut jenis kelamin, usia dan nilai spastisitas menggunakan statistik deskriptif

2. Pada Kelompok I dan Kelompok II hasilnya adalah data berdistribusi normal $(\mathrm{p}>0,05)$ dan selanjutnya dilakukan uji parametrik. Uji Normalitas Data dengan Shapiro Wilk Test.

3. Levene's Test digunakan untuk mengetahui data bersifat homogen atau tidak. Hasil yang didapatkan bahwa sebaran data bersifat homogen yaitu $\mathrm{p}>$ 0,05

4. Uji hipotesis I membuktikan stimulation attitudional reflex exercise dalam meningkatkan head control pada anak CP. Untuk menguji kemaknaan data Kelompok I sebelum dan setelah pemberian intervensi menggunakan paired sample t-test.

5. Uji hipotesis II membuktikan prone position wedge exercise dalam meningkatkan head control pada anak CP. Untuk uji kemaknaan data pada Kelompok II sebelum dan setelah pemberian intervensi menggunakan paired sample t- test.

6. Uji hipotesis III untuk membuktikan stimulation attitudional reflex exrecise lebih baik dari pada prone position wedge exercise dalam meningkatkan head control pada anak CP. Uji kemaknaan 2 sampel yang tidak berpasangan pada Kelompok I dan Kelompok II menggunakan independent sample t-test

\section{HASIL PENELITIAN}

\section{Deskripsi Karakteristik Subjek}

Subjek penelitian adalah anak CP spastik quadriplegi dengan gangguan head control terbagi menjadi II kelompok, masing - masing terdiri dari 12 anak.

Deskripsi data berupa karakteristik subjek penelitian meliputi : jenis kelamin, usia, dan nilai spastisitas bisa dilihat pada Tabel 1 .
Tabel 1. Subjek Berdasarkan Jenis

Kelamin, Usia, dan Nilai Spastisitas

\begin{tabular}{|c|c|c|c|c|c|}
\hline \multirow{3}{*}{ Karakteristik } & \multirow{3}{*}{ Kategori } & \multicolumn{2}{|c|}{ Frekuensi } & \multicolumn{2}{|c|}{ Persen $(\%)$} \\
\hline & & Kel & Kel & Kel & Kel \\
\hline & & 1 & 2 & 1 & 2 \\
\hline \multirow{2}{*}{$\begin{array}{c}\text { Jenis } \\
\text { kelamin }\end{array}$} & Laki-laki & 5 & 7 & 41,7 & 58,3 \\
\hline & Perempuan & 7 & 5 & 58,3 & 41,7 \\
\hline \multirow{3}{*}{ Usia } & $\begin{array}{l}0,6-2 \\
\text { tahun }\end{array}$ & 3 & 5 & 25 & 41,7 \\
\hline & $\begin{array}{l}2,1-3,5 \\
\text { tahun }\end{array}$ & 6 & 2 & 50 & 16,7 \\
\hline & $\begin{array}{l}3,6-5 \\
\text { tahun }\end{array}$ & 3 & 5 & 25 & 41,7 \\
\hline \multirow{6}{*}{$\begin{array}{c}\text { Nilai } \\
\text { spastisitas }\end{array}$} & 0 & 0 & 0 & 0 & 0 \\
\hline & 1 & 7 & 8 & 58,3 & 66,7 \\
\hline & $1+$ & 0 & 0 & 0 & 0 \\
\hline & 2 & 5 & 4 & 41,7 & 33,3 \\
\hline & 3 & 0 & 0 & 0 & 0 \\
\hline & 4 & 0 & 0 & 0 & 0 \\
\hline
\end{tabular}

Tabel 1 menunjukkan bahwa pada Kelompok I maupun Kelompok II subjek penelitian menurut jenis kelamin terbagi rata yaitu $58,3 \%$ berjenis kelamin lakilaki pada kelompok II dan 58,3\% berjenis kelamin perempuan pada Kelompok I. Distribusi data berdasarkan usia menunjukkan rentang usia 2,1-3,5 tahun sangat dominan yaitu berjumlah 6 anak pada Kelompok I (50\%), kemudian distribusi data berdasarkan nilai spastisitas yang diukur dengan skala ashworth yang paling dominan adalah dengan nilai spastisitas 1 pada kelompok II $(66,7 \%)$. 
2. Uji Normalitas Data dan Homogenitas Data

Uji normalitas data menggunakan Shapiro Wilk test, sedangkan uji homogenitas menggunakan Levene's test yang hasilnya bisa dilihat pada Tabel 2 .

Tabel 2. Uji Normalitas dan Homogenitas

Data Head Control Anak CP Spastik Quadriplegi

\begin{tabular}{cccccc}
\hline & \multicolumn{2}{c}{$\begin{array}{c}\text { Uji Normalitas dengan Shapiro } \\
\text { Wilk Test }\end{array}$} & $\begin{array}{c}\text { Uji } \\
\text { Homogenitas } \\
\text { Kel }\end{array}$ \\
\cline { 2 - 4 } Data & Kel 1 & \multicolumn{2}{c}{ Kel 2 } & $\begin{array}{c}\text { Lene's } \\
\text { test) }\end{array}$ \\
& $\begin{array}{c}\text { Rerata } \\
\pm \mathrm{SB}\end{array}$ & $p$ & $\begin{array}{c}\text { Rerata } \\
\pm \mathrm{SB}\end{array}$ & $P$ & $p$ \\
& & & & \\
\hline Skor & $45,08 \pm$ & 0,387 & $43,15 \pm$ & 0,231 & \\
Pre & 9,90 & & 1,09 & & 0,654 \\
& & & & & \\
Skor & $78,27 \pm$ & 0,078 & $60,11 \pm$ & 0,124 & \\
Post & 7,45 & & 1,01 & &
\end{tabular}

Pada Tabel 2 dapat disimpulkan bahwa semua data berdistribusi normal $(p>0,05)$ dan bersifat homogen ( $p>0,05)$.

3. Pemberian stimulation attitudional reflex exercise dan prone position wedge exercise dapat meningkatkan kemampuan head control pada anak CP spastik quadriplegi

Rerata peningkatan nilai head control pada Kelompok I dan Kelompok II sebelum dan setelah perlakuan yang diuji dengan Paired Sample t-test bertujuan untuk melihat perbedaan nilai rata-rata peningkatan head control sebelum dan setelah diberikan intervensi bisa dilihat di Tabel 3.
Tabel 3. Hasil Uji Paired Sampel T-Test Pada Kelompok I dan II

\begin{tabular}{cccc}
\hline \multirow{2}{*}{ Kelompok } & $\begin{array}{c}\text { Sebelum } \\
\text { Perlakuan }\end{array}$ & $\begin{array}{c}\text { Setelah } \\
\text { Perlakuan }\end{array}$ & \multirow{2}{*}{$p$} \\
\cline { 2 - 3 } & $\begin{array}{c}\text { Nilai Rerata } \pm \\
\text { SB }\end{array}$ & $\begin{array}{c}\text { Nilai } \\
\text { Rerata } \pm \text { SB }\end{array}$ \\
\hline I & $45,08 \pm 9,90$ & $78,27 \pm 7,45$ & 0,001 \\
II & $43,15 \pm 10,92$ & $60,11 \pm 10,19$ & 0,001
\end{tabular}

Tabel 3 didapatkan hasil yang sama terhadap 2 kelompok yaitu $\mathrm{p}=0,001$ ( $\mathrm{p}<$ $0,05)$ maka ada pengaruh peningkatan nilai head control sebelum dan setelah perlakuan.

4. Perbedaan pengaruh peningkatan nilai head control sebelum dan sesudah pemberian stimulation attitudional reflex exercise dan prone position wedge exercise terhadap kemampuan head control pada anak CP spastik quadriplegi

Perbedaan peningkatan nilai head control pada Kelompok I dan II sebelum dan setelah pemberian intervensi diuji dengan Independent t-test. Hasil uji tertera pada Tabel 4

Tabel 4. Hasil Uji Dengan Menggunakan Independent t-test Pada Kelompok I dan II

\begin{tabular}{|c|c|c|c|}
\hline \multirow{3}{*}{$\begin{array}{c}\text { Kelompok } \\
\text { Data }\end{array}$} & Kelompok & Kelompok & \multirow{3}{*}{$p$} \\
\hline & & & \\
\hline & $\begin{array}{c}\text { Nilai Rerata } \\
\pm \text { SB }\end{array}$ & $\begin{array}{c}\text { Nilai Rerata } \pm \\
\text { SB }\end{array}$ & \\
\hline $\begin{array}{c}\text { Sebelum } \\
\text { Perlakuan }\end{array}$ & $45,08 \pm 9,90$ & $43,15 \pm 10,92$ & 0,654 \\
\hline $\begin{array}{c}\text { Setelah } \\
\text { Perlakuan }\end{array}$ & $78,27 \pm 7,45$ & $60,11 \pm 10,19$ & 0,001 \\
\hline
\end{tabular}

Tabel 4 nilai head control sebelum perlakuan didapatkan nilai $\mathrm{p}=0,654(\mathrm{p}>$ 
$0,05)$ yang berarti tidak ada perbedaan bermakna, sedangkan untuk nilai head control setelah perlakuan didapatkan nilai $\mathrm{p}=0,001(\mathrm{p}<0,05)$ yang berarti ada perbedaan bermakna pada kedua kelompok perlakuan tersebut setelah diberikan intervensi.

5. Stimulation attitudional reflex exercise lebih baik dibandingkan dengan prone position wedge exercise terhadap head control pada anak CP spastik quadriplegi

Untuk mengetahui bahwa stimulation attitudional reflex exercise lebih baik dibandingkan dengan prone position wedge exercise yaitu menggunakan rerata nilai peningkatan kemampuan head control setelah diberikan intervensi. Hasil nilai tertera pada Tabel 5

Tabel 5. Nilai Presentase Peningkatan Head Control Setelah Diberikan Intervensi

\begin{tabular}{cccc}
\hline Kelompok & $\begin{array}{c}\text { Sebelum } \\
\text { Perlakuan } \\
(\%)\end{array}$ & $\begin{array}{c}\text { Setelah } \\
\text { Perlakuan } \\
(\%)\end{array}$ & $\begin{array}{c}\text { Nilai } \\
\text { Peningkatan } \\
(\%)\end{array}$ \\
\hline I & 45,08 & 78,27 & 33,19 \\
II & 43,15 & 60,11 & 16,96 \\
\hline
\end{tabular}

Tabel 5 dapat disimpulkan bahwa pada Kelompok I lebih besar nilai peningkatan yaitu 33,19\% dibandingkan dengan Kelompok II sebesar 16,96\%. Jadi dapat disimpulkan bahwa Kelompok I stimulation attitudional reflex exercise lebih baik dibandingkan dengan Kelompok II prone position wedge exercise terhadap peningkatan head control pada anak $\mathrm{CP}$ spastik quadriplegi di RS Rajawali Citra Bantul, Yogyakarta

\section{PEMBAHASAN}

1. Stimulation attitudional reflex exercise meningkatkan kemampuan head control pada anak CP spastik quadriplegi

Analisis data persentase nilai kemampuan head control dengan pemberian stimulation attitudional reflex exercise antara tes awal dengan tes akhir paired sample t-test didapatkan nilai $\mathrm{p}=$ $0,001$ ( $\mathrm{p}<0,05)$ artinya ada peningkatan kemampuan head control pada anak $\mathrm{CP}$ spastik quadriplegi.

Penelitian ini sesuai dengan penelitian yang dilakukan oleh Tsorlakis yaitu kematangan reflex bayi pertama kali ada ditingkat spinal yaitu berupa reflex rooting dan sucking yang harus terintegrasi menuju ke level brainstem menjadi ATNR kemudian akan digantikan reflex fisiologis berupa rolling dan prone membentuk head control untuk memperoleh struktur sensomotor reflex yang bagus. Head control merupakan tahap awal untuk menuju reflex ditingkat midbrain seperti duduk dan kneeling, untuk memperoleh head control yang bagus maka diperlukan adanya stimulation attitudional reflex yang sesuai dengan stimulus sensoris. ${ }^{9}$

2. Prone position wedge exercise dapat meningkatkan kemampuan head control pada anak CP spastik quadriplegi

Hasil penelitian dari data persentase nilai kemampuan head control pada prone position wedge exercise selama 6 minggu didapatkan rerata hasil sebelum perlakuan sebesar 43,15 $\pm 10,92 \%$ dan setelah perlakuan sebesar $60,11 \pm 10,19 \%$ artinya ada perbedaan rerata persentase nilai kemampuan head control sebelum dan setelah perlakuan. Hasil analisis data hipotesis nilai kemampuan head control dengan intervensi prone position wedge exercise antara tes awal dengan tes akhir 
yang diuji dengan paired sample t-test didapatkan nilai $\mathrm{p}=0,001(\mathrm{p}<0,05)$ dapat disimpulkan bahwa prone position wedge exercise dapat meningkatkan kemampuan head control

Hasil penelitian tersebut sesuai dengan yang penelitian yang dilakukan oleh Linda Dudek dan Perez Machado yaitu membandingkan prone position exercise dengan kelompok kontrol terhadap bayi sehat pada bulan pertama hingga ketiga setelah lahir. Hasil penelitian tersebut menunjukkan hasil yang signifikan pada kelompok prone position exercise dibandingkan kelompok kontrol dalam rentang waktu setelah usia 3 bulan sangat efektif pada perkembangan head control

Tumbuh kembang head control sangat bagus pada posisi tengkurap dibandingkan dengan terlentang pada bayi karena akan meningkatkan resiko angka kejadian deformational plagiochepaly (kepala bayi yang berbentuk datar atau tidak sempurna) dan positional toriticollis (lemahnya otot leher bayi yang mengakibatkan ototnya terpelintir). ${ }^{8,10}$

3. Stimulation attitudional reflex exercise lebih baik dibandingkan dengan prone position wedge exercise terhadap head control pada anak CP spastik quadriplegi

Nilai hasil uji perbedaan menggunakan independent sample t-test didapatkan nilai $\mathrm{p}=0,001$ dimana $(\mathrm{p}<0,05)$, artinya terdapat perbedaan yang signifikan antara Kelompok I dengan Kelompok II terhadap peningkatan nilai head control pada anak CP spastik quadriplegi.

Berdasarkan nilai rerata pada kedua kelompok perlakuan tersebut, Kelompok I mengalami peningkatan head control yang lebih besar besar yaitu 33,19\% dibandingkan dengan Kelompok II yang hanya mempunyai nilai $16,96 \%$, maka dapat disimpulkan bahwa stimulation attitudional reflex exercise lebih baik dibandingkan dengan prone position wedge exercise terhadap peningkatan head control

Hasil penelitian tersebut sesuai dengan teori dan tindakan intervensi yang dilakukan oleh Svetlana Masgutova tentang tentang proses pembelajaran reflex primitif terlebih dahulu. Prinsip stimulation attitudional reflex exercise ada didalam pembahasan reflex repatterning dan sensory integration yang bertujuan untuk mengintegrasikan reflex ATNR, STNR, dan TLR menjadi reflex fisiologis berupa rolling, prone dan head control yang bagus dibandingkan dengan latihan yang bersifat fungsional tanpa diikuti kematangan reflex yang dimiliki pada masing-masing anak $\mathrm{CP}$ untuk memperoleh normal postural reflex mekanisme yang bagus. ${ }^{11}$

Hasil penelitian, teori dan tindakan intervensi tersebut diperkuat lagi hasil penelitian yang dilakukan oleh Kyoung Hwan Lee tentang neurodevelopment postural control yaitu kematangan head control yang mana mekanismenya mendapatkan informasi dari sistem visual dan vestibular yang bertujuan untuk memberikan pembelajaran motor kontrol dalam hubungannya dengan maturitas reflex yang tertata dengan baik. ${ }^{12}$

Hasil teori dan penelitian itu, penulis menyimpulkan bahwa pendekatan stimulation attitudional reflex exercise lebih baik dibandingkan dengan prone position wedge exercise karena terjadi proses pembelajaran reflex yang dimulai dari tingkat dasar hingga reflex pada tingkat lanjutan yang selalu berkesinambungan untuk memperoleh postural kontrol yang bagus sehingga kemampuan anak $\mathrm{CP}$ spastik quadriplegi yang belum matang pada level brainstem akan terus menerus terstimulasi proses pembelajaran sesuai dengan teori plastisitas otak.

Plastisitas otak terbentuk oleh adanya proses motor relearning program setelah terjadi kerusakan otak yang mengakibatkan 
penurunan kemampuan head control pada anak CP spastik quadriplegi. Tahap pastisitas otak pada pemberian stimulation attitudional reflex exercise berpengaruh pada efek fisiologis berupa penurunan kontraktur sendi oleh karena spastisitas dan mobilitas leher yang bagus selama tahap tahap stimulasi latihan untuk memperoleh sinaps sinaps yang dibawa ke otak sebagai proses belajar dari kerusakan sehingga head control pada anak $\mathrm{CP}$ spastik quadriplegi mengalami peningkatan.

\section{SIMPULAN}

1. Stimulation attitudional reflex exercise meningkatkan head control pada anak CP spastik quadriplegi di RS Rajawali Citra Bantul, Yogyakarta

2. Prone position wedge exercise meningkatkan head control pada anak CP spastik quadriplegi di RS Rajawali Citra Bantul, Yogyakarta

3. Stimulation attitudional reflex exercise lebih baik dibandingkan dengan prone position wedge exercise terhadap head control pada anak $\mathrm{CP}$ spastik quadriplegi di RS Rajawali Citra Bantul, Yogyakarta

\section{DAFTAR PUSTAKA}

1. Angermeier, K. 2013. Infant PositioningAndDevelopmant.https://occ upationaltherapy.advanceweb.com/Arch ives/Article-Archives/ InfantPositioning-And development. Aspx Diakses 27 Oktober 2017

2. Butler, C. 2001. The effect Neurodevelopmental Treatment For CP. evidence repoet. Developmental Medical Children Neurologic Journal. Volume 43(11): 778-90.

3. Chavan, S. 2006. Head Control For Pylot Study Clinical Rating Scale. Indian Journal Occupational Therapy (OT) Indian, Volume XXXIX : 3.

4. Dewey, C.2008. Sleeping Position adverse effects on the child developmental in the first 18 month. Pediatrics, 101, 5-12

5. Shamsoddini,A. 2014. Management of Spasticity in CP. Iran Journal Pediatric. Volume 24 (4) : 345-351

6. Sina, L. 2015. The Effect of NDT on GMFM in CP. Iran Journal Children Neurologic. Iran, 9 (1) : 36-41.

7. Song, C. 2013. Activity Daily of Living in CP. Journal Physical Therapy Science. Volume 25 (5) : 619 - 22.

8. Dudek, L. 2008. The Effect Of Prone Position On Developmental Milestone. Pediatric Physical Therapy. American, 19 (1) : 48-55

9. Tsorlakis,N. 2014. The Effect of intensive NDT in GMFM of CP. Developmental Medicine Children Neurologic. Volume 46(11):740-5.

10. Machado, P. 2011. Prone position relationship and achieving At 3 Month. Journal Pediatric (Barc) Spain. 79 (4) 241-7

11. Masgutova, S., dan Akhmatova. 2011. Sensoris Integration in CP. Warsawa, Polandia : MINK. p. 14-28.

12. Lee, K. 2016. The Effect NDT For Delay Development And CP. Ann Rehabilitation Medical. South Korea,Volume 41(1) : 90 - 96. 